\title{
“Perder respeto a ley severa» en la poesía argentina de Gelman y Lamborghini
}

\author{
Lucía Cotarelo Esteban \\ Universidad Complutense de Madrid \\ Facultad de Filología \\ Departamento de Filología Española II \\ (Literatura Española) \\ Plaza Menéndez Pelayo s/n, Edificio D \\ Ciudad Universitaria \\ 28040 Madrid \\ luciacotarelo@ucm.es
}

[La Perinola, (Issn: 1138-6363), 22, 2018, pp. 443-457]

DOI: $10.15581 / 017.22 .443-457$

\section{Quevedo EN LA Literatura hispanoAMERICANA}

El influjo de la obra quevedesca en la literatura hispanoamericana dio sus primeros frutos con la temprana producción del siglo XVII de escritores de la época colonial, como recogen Herrera (2003) y García Valdés (2009), entre otros. Sin embargo, tanto los modelos seguidos por la extensa nómina de autores ofrecida por García Valdés ${ }^{1}$, como la clara presencia de Quevedo son difícilmente identificables, situación que Herrera atribuye a una homogeneidad cultural de la época barroca, y a la contrapuesta heterogeneidad de la producción quevedesca, con la consecuente amplitud de temas y tonos, que van desde lo festivo y satírico hasta lo hondo y torturado. Herrera señala también la presencia de los ecos quevedescos en salmos bíblicos de finales del siglo XVI, y en las canciones pindáricas de principios del xviıI.

Las resonancias del poeta persistieron en los siglos siguientes en los poemas amorosos y más existencialistas de Rubén Darío como los «Nocturnos», «Lo fatal» o “La dulzura del Ángelus», como advierte Acereda (2001). Las primeras décadas del siglo xx respondieron en Hispanoamérica, como en el panorama cultural peninsular, a un espíri-

1. Juan del Valle y Caviedes, sor Juana Inés de la Cruz, fray Joaquín Bolaños, José Mariano Acosta, Alonso Carrió de la Vandera, Juan Bautista Aguirre, Gregorio de Matos, Álvarez de Velasco, Antonio Paz y Salgado, Luis de Sandoval y Zapata, Juan Mogrovejo, o Fernández de Lizardi. Ver García Valdés, 2009, p. 18. 
tu ecléctico - tan característico de la Modernidad- reivindicador de la tradición literaria española, que puso especial énfasis en la recuperación de las poéticas de los Siglos de Oro. Bellini (1976) recoge en su estudio algunos de los productos de estas recuperaciones en poetas hispanoamericanos de gran renombre como César Vallejo, Jorge Carrera Andrade, Octavio Paz, Pablo Neruda y Borges, entre cuyos versos detecta rastros a veces francamente reveladores de la poética quevedesca -en la inmensa mayoría de los casos pertenecientes a su obra más solemne y existencial, tocantes a la muerte, el tiempo, la soledad humana y el tópico de la ceniza- ${ }^{2}$.

Avanzando en el tiempo -y focalizando el espacio-, la producción literaria argentina de las décadas de los 70 y 80 se vio inevitablemente afectada por este influjo general, mas fueron el viraje político del país y la experiencia vital de sus poetas los que determinaron la vuelta a una poética recuperadora de los principios estéticos del Barroco. El panorama poético de las décadas de los 60, 70 y 80 parte de una etapa estable y concretizada en corrientes artísticas definidas, evoluciona hacia una época más voluble, y vuelve a reorganizarse enriquecida y más variada.

En los años 60, gran parte de la producción literaria se adscribió a una corriente regida por la premisa del compromiso con la época, que trató de reflejar los acontecimientos políticos y sociales de la misma. En los años 70, el ambiente de represión y censura, las detenciones, los asesinatos, desapariciones y exilios hicieron mella en las anteriores concepciones literarias definidas y establecidas, que fueron cuestionadas, provocando un momento de incertidumbre creativa, falto de una poética o programa general. Aquel sistema y sus concepciones poéticas dejaron de configurarse como moldes expresivos válidos, y precisaron de una renovación; asimismo se vieron debilitadas la actividad editorial y la práctica artística misma hasta unos años después del golpe.

Si durante la década anterior se había impuesto un lenguaje natural y claro que rozaba lo coloquial, en los años 70 el lenguaje poético se distanció del conversacional siguiendo a veces una línea vanguardista, pasando a tornarse evasivo, oscuro, ambiguo, recuperando la antigua

2. Así por ejemplo en poemas de Carrera Andrade como «Polvo, cadáver del tiempo» y «Tres estrofas al polvo», y en poemarios de los años 60 como El alba llama a la puerta y Libro del destierro. Neruda se confesó innegable lector de Quevedo en los poemas teñidos de sombrías tonalidades cenicientas de Residencia en la tierra (1934), y siempre admirador de su creación poética en «Viaje al corazón de Quevedo» (contenido en Viajes). La vida es «agricultura de los huesos» - como la (agricultura de la muerte» quevedesca-, la muerte es presencia ubicua durante la vida - «veo las muertes que están entre nosotros desde ahora / y respiro en el aire la ceniza y lo destruido» («Tango del olvido»)-, el tiempo es corrosivo de todo lo mundano - «todo se cubre de sabor mortal cuando el tiempo le pasa su lengua de polvo podrido» («La calle destruida»)-, pero el amor perdura en la muerte "Alguna vez si ya no somos, / si ya no vamos ni venimos / bajo siete capas de polvo / y los pies secos de la muerte, / estaremos juntos, amor, / extrañamente confundidos» («Testamento de otoño»). 
retórica barroca ${ }^{3}$ y romántica que había sido sustituida en los 50 y 60: “Incertidumbre, desconfianza, abordaje oblicuo del discurso, enmascaramiento, fractura, desplazamiento de los grandes temas a la propia subjetividad, búsqueda de un centro ubicado fuera del entorno social inmediato» ${ }^{4}$. Nacían los antecedentes de la reaparición del barroco (Chiampi, 2000) en un estilo neobarroco caracterizado por un «abandono del tono coloquial, la estructura narrativa y la intención comunicativa en el discurso poético», con intención de «romper con la sintaxis y profundizar los ritmos y las sonoridades», plagado de «elipsis que discurren en la corriente de significantes del poema, transformado en un continuo fluir de palabras abandonadas por la denotación y sometidas a lo impredecible de la connotación», y por «la presencia de lo político y lo ideológico en el texto» ${ }^{5}$.

\section{Dos ReEscrituras argentinas}

El tiempo, el polvo, y la muerte despuntaban, como avisaba ya Bellini (1976) entre los versos de Octavio Paz, encontrándose una mención directa de Quevedo con el soneto «Amor constante más allá de la muerte» en calidad de epígrafe de la sección «Homenaje y profanaciones» en Salamandra:

Blancura de aguas muertas,

Hora blanca, ceguera de los ojos abiertos.

Frota tu pedernal, arde memoria,

Contra la hora y su resaca,

Memoria, llama nadadora.

Desatado del cuerpo, desatado

Del ansia, vuelvo al ansia, vuelvo

A la memoria de tu cuerpo. Vuelvo.

$\mathrm{Y}$ arde tu cuerpo en mi memoria,

Arde en tu cuerpo mi memoria.

Cuerpo de un Dios que fue cuerpo abrasado,

Dios que fue cuerpo y fue cuerpo endiosado

Y es hoy tan sólo la memoria

De un cuerpo desatado de otro cuerpo:<smiles>C1=CCCC1</smiles>

Mas la memoria desmembrada nada

3. El espíritu barroco se manifiesta especialmente donde hay transformación, innovación, se proyecta hacia delante, y fue por ello que el momento histórico que se desarrollaba en Argentina durante esta década propició que se recuperaran sus elementos. Cabe apuntar en cuanto a esto, que en la poesía argentina se produjo, como ocurre a lo largo de la historia de la literatura, una oscilación entre las dos constantes humanas de las que hablaba Alejo Carpentier (2003): el espíritu clásico (equilibrio, armonía, academicista) y el barroco (horror al vacío y la armonía, dinamismo, proliferación de elementos) que se alternan cíclicamente y vuelven por medio de las manifestaciones artísticas a lo largo de la historia.

4. Fondebrider, 2001, p. 13.

5. Vázquez, 2007, s/p. 
Desde los nacederos de su nada

Los manantiales de su nacimiento

Nada contra corriente y mandamiento

$[\ldots]$

ojos medulas sombras blanco día ansias afán lisonjas horas cuerpos memoria todo Dios ardieron todos polvo de los sentidos sin sentido ceniza de lo sentido y el sentido ${ }^{6}$.

El poema sigue, como los que se analizarán a continuación, varios procedimientos para integrar ciertos aspectos de la poética quevedesca y de la composición mencionada:

a. La recuperación léxica de ciertos términos más generales como memoria, sombra, cuerpo, ojos, y otros más particulares que combinados con los anteriores remiten al lector inmediatamente a Quevedo, aunque a veces trastocados por cambios morfológicos o por la distinta distribución de sus componentes: “día blanco», "medulas», «lisonjas», "polvo de los sentidos», (calma desatada», (arde memoria», etc.

b. La recuperación de conceptos que pueden variar sus connotaciones y significado o mantener los originales, como el ardor y el fuego vinculados al amor, causantes de la consumición del amante - «arde tu cuerpo en mi memoria»-, la de la rebelde llama-memoria -«memoria, llama nadadora [...] nada contra corriente y mandamiento»-, o la del "polvo enamorado» - (polvo de los sentidos [...] ceniza de lo sentido y el sentido»-.

c. El empleo de estructuras y recursos retóricos similares, como los paralelismos sintácticos, los encabalgamientos abruptos, los intensos hipérbatos, las antítesis y las reiteradas hipérboles: «Sombras del día blanco / contra mis ojos. Yo no veo / nada sino lo blanco / la hora en blanco. El alma / desatada del ansia y de la hora»; “Cuerpo de un Dios que fue cuerpo abrasado"; "polvo de los sentidos sin sentido / ceniza de lo sentido y el sentido».

d. Resulta también significativa la forma en la que las infinitas combinaciones de la terminología quevedesca desembocan en la creación de neologismos - habituales también en la producción de Quevedo- por el procedimiento de la composición de lexemas, dando lugar a un nuevo vocabulario de esencia antitética que provoca extrañeza y abre un nuevo mundo de posibilidades existenciales y sentimentales: «Sombra del sol Solombra segadora / ciega mis manantiales trasojados».

e. Y sin duda, Octavio Paz recupera el tono general de pesadumbre, y las connotaciones de las que la tradición, ya consagrada por este soneto, dota a sus palabras.

En estas estrofas Paz mantiene, aun ofreciendo variaciones significativas con respecto al contenido total del poema quevedesco, la temática

6. Octavio Paz, «Salamandra» (1958-1961), La centena (Poemas de 1935-1968), Barcelona, Barral Editores, 1969. 
amorosa original. Como él, otros poetas españoles e hispanoamericanos han encontrado en este soneto la fuente adecuada para hacer despegar sus propias composiciones, o para tomar sus ya consagrados tópicos como el del «polvo enamorado»- y lenguaje. No siempre ha sido mantenida, sin embargo, esa temática: resulta sorprendente el modo en que algunos poetas hispanoamericanos han encontrado en "Amor constante más allá de la muerte» el medio adecuado para arrancar la escritura de poemas desgarrados que nacen, como los de Juan Gelman y Leónidas Lamborghini, de la experiencia traumática de la dictadura?.

La faceta política de Quevedo es de sobra conocida, tanto a través de su producción literaria como de los acontecimientos biográficos que de él se conocen. Como recordaba Blecua ${ }^{8}$ la política fue, siempre junto a la literatura, una de las grandes preocupaciones del poeta, lo que le caracteriza como un autor estrechamente ligado a su tiempo. Ambas facetas tan de su interés no estuvieron, por lo tanto, reñidas en absoluto, y no serían los poemas a continuación analizados los primeros que recogiesen tópicos empleados por Quevedo para tratar asuntos políticos o sociales. Puede por estas cuestiones y por las siguientes, que no deba sorprender tanto el modo en que lo amoroso quevedesco es sensible a tornarse político y reivindicativo: «Amor constante más allá de la muerte» no es sólo el poema amoroso de aceptación estoica de la muerte, es un poema eminentemente de lucha, de inconformismo e insubordinación, de enfrentamiento no a la muerte pero sí a sus consecuencias: el fin del amor, la llegada del olvido.

La ambigüedad de ciertos tópicos y este tono predominante hacen posible una reinterpretación, por ejemplo, de las partes de la ribera, el agua fría, la sombra o la ley severa, que pueden despojarse de su esencia metafórica para tornarse riberas ciertas del exilio, agua fría del Río de la Plata a donde los «subversivos» eran arrojados, sombra de la prisión, ley severa del estado terrorista ${ }^{9}$. Asimismo, la faceta metafísica

7. La turbulenta historia del siglo xx argentino estuvo inscrita en un panorama general de violencia política: golpes de estado, gobiernos militares y represión fueron las señas de identidad del Cono Sur durante décadas. El golpe militar de 1976 fue el sexto acontecido desde comienzos del siglo, y el régimen militar que le siguió, dirigido por una Junta militar encabezada por comandantes de las tres Fuerzas Armadas, con el teniente general José Rafael Videla a la cabeza, se extendió hasta 1983 y fue uno de los más violentos de todos los tiempos en América del Sur. Le precedía el inestable gobierno de María Estela Martínez de Perón, fortalecido por grupos de derechas y comandos de represión, como la fuerza parapolicial Triple A, en constante pugna con toda la oposición, a veces organizada en grupos guerrilleros como los Montoneros.

8. Blecua, “Introducción» a Quevedo, 1976.

9. Con el golpe de estado nació un régimen militar autodenominado «Proceso de Reorganización Nacional», una de las estrategias expresivas de las que se sirvió el discurso de los vencedores para envolver a través de eufemismos y metáforas la realidad dictatorial; maniobras políticas que inauguraron su intención de restablecer el orden y la seguridad del país a través del sometimiento de la población mediante el terror, sembrado en la lucha contra los «subversivos», concepto que dejaron definido en un sentido muy amplio, incluyendo en él a simpatizantes de cualquier movimiento de crítica social, o simplemente 
del poema -con aquellas frustradas polémicas entre el dualismo o monismo del ser- da cabida a una nueva y compleja realidad humana de fusión y unificación antitética, esta vez no de alma y cuerpo, sino de vida y muerte que la dictadura impone: el estado del «desaparecido» ${ }^{10}$.

\subsection{Leónidas Lamborghini}

Como para Quevedo, la política ocupó un lugar principal en la vida y obra de Leónidas Lamborghini ${ }^{11}$. La suya era, antes del golpe de estado de 1976, una escritura ya politizada: el discurso cotidiano, el periodístico, el del tango, emergieron entre sus versos junto a los clichés del discurso político, desautorizando estos modelos del poder, creando transgresoras caricaturas y parodias del género. "Violencia contra violencia», en palabras del poeta, poesía destructora que retuerce la sintaxis de los mensajes del sistema de su época para acabar con la voz impuesta por el poder $^{12}$. Siguiendo estos modelos, El Solicitante descolocado nació como una variación del discurso político, y diversos textos fueron susceptibles de politizarse, incluso tangos de tema amoroso, como sucede en «En la subasta» ${ }^{13}$. Las fuentes de Lamborghini fueron muy variadas, y entre ellas tuvieron cabida la poesía gauchesca, el tango, la poesía clásica, la poesía barroca, la modernista. A pesar de su vinculación estética a grupos vanguardistas como «Poesía Buenos Aires», en cuyas reuniones participaba, nunca adoptó su carácter rupturista, optando por un eclecticis-

sospechosos de serlo - esto es, a todo ciudadano-. Se impuso así el terrorismo de Estado. Desde el primer día se llevaron a cabo detenciones y secuestros clandestinos ilegales que fueron encubiertos como acciones antisubversivas, apoyadas en herramientas como la Operación Cóndor y los centros clandestinos de tortura; uno de los métodos habituales para deshacerse de los cadáveres fueron los llamados «vuelos de la muerte», durante los cuales los militares arrojaban desde aviones a los «subversivos», a veces todavía vivos, al Río de la Plata; los civiles secuestrados, torturados, asesinados, pasaron a denominarse eufemísticamente “desaparecidos». No existían cadáveres que pudieran constatar sus muertes, y por lo tanto no había posibilidad de confirmar un crimen ni de castigarlo.

10. Decía el general Videla al respecto en sus conversaciones con el periodista Guido Braslavsky entre 1998 y 1999: «¿Dar a conocer dónde están los restos? Pero ¿qué es lo que podíamos señalar? ¿El mar, el Río de la Plata, el Riachuelo? Se pensó, en su momento, dar a conocer las listas. Pero luego se planteó: si se dan por muertos, enseguida vienen las preguntas que no se pueden responder: quién mató, dónde, cómo» (Seoane, 2001). Manifestaba así la irregularidad en la que fueron cometidos estos asesinatos, y la comodidad que suponía para el Estado criminal darles el tratamiento de «desaparecidos». Nacía también una incógnita, nuevamente una comodidad para el asesino, pero también una tremenda incertidumbre para la población, en la liviandad de las palabras de Videla: «es una incógnita $[\ldots]$ no tiene entidad, no está ni muerto ni vivo, está desaparecido».

11. Poeta y periodista, hubo de exiliarse a México en 1977 debido a su militancia política, volviendo a Argentina en 1990.

12. Fue por ejemplo el caso de la Marcha Peronista, el Himno Nacional Argentino, o de su «Eva Perón en la hoguera», nacido de aquel La razón de mi vida, obra autobiográfica encargada para Eva Perón publicado en 1951.

13. Porrúa, 2001, pp. 153-155. 
mo que permitió una gran mescolanza de tradiciones en su obra ${ }^{14}$. Las diversas voces se yuxtaponen y mezclan creando un texto heterogéneo formal, temática y semánticamente quebrado: este proceso de lectura y tratamiento del original queda unificado a través de la creación del personaje poético: «la lectura de Lamborghini aliena el texto original [...] la voz -el tratamiento de la voz- es el personaje [...] voz indirecta bajo la pauta del artificio» ${ }^{15}$. El yo poético adopta los discursos ajenos apropiándose de ellos a través de la deconstrucción, de la inversión, del corte, del montaje a modo de collage, y a menudo de la parodia; puede suponer una "variación como comentario», interpretación que respeta en gran parte la integridad del original, o una "variación como distorsión» que desnaturaliza y destruye el texto original ${ }^{16}$. Ricardo González (1998) distingue los tres procedimientos más habituales para llevar a cabo estas reescrituras: repetición -como «explotación de lo semántico [que] termina a menudo creando un signo propios-, aliteración - creando una “corriente de sonidos» cohesionadora-, y ruptura -mutilación de los versos e incluso de las palabras, dislocación de la sintaxis, elipsis e interrupciones bruscas, fragmentación de los versos que aísla el segmento que adquiere un nuevo sentido, juegos de ambivalencia-, procedimientos que bien podrían recordar a algunos propios de las estéticas barrocas.

«LAS DOS ORILLAS»

I

de esotra parte en la ribera:

alma desatada. venas que han. médulas: lo ardido

que han: desatadas:

gloriosamente.

II

la llama que nada en agua fría

de esotra parte. la Llama que llama:

un todo Dios-Llama que llama:

de esotra. el alma desatada

que fue prisión de un todo

Llama: un Dios todo.

III

de esotra parte: el humor: la llama

en agua. un Dios-Llama nadando en Agua Fría

gloriosamente:

desatado.

14. Esta gran variedad puede apreciarse en antologías como El genio de nuestra raza. Las reescrituras de Leónidas Lamborghini, donde emergen pasajes de Quevedo, Góngora, Keats, del Martín Fierro, de los tangos, incluso de la correspondencia del propio Van Gogh.

15. Porrúa, 2001, pp. 30-31.

16. Porrúa, 2001, pp. 45-51. 
IV

mas no de estotra parte en la ribera.

de estotra parte: alma-prisión. la postrera

sombra que puede: ley

severa.

V

mas de esotra parte: gloriosamente médulas ardiendo. gloriosamente venas. gloriosamente cuerpo desatado. polvo y ceniza: gloriosamente ardiendo.

VI

de esotra: un Dios-Toda-Llama

que llama nadando

enamorado. un Dios-Llama

que ardiendo: con médulas. con venas. con humor: el respeto perdido a ley severa. la llama

que nada. un Dios-Llama nadando enamorado

en Agua Fría. Un Dios Todo que es Cuerpo

Enamorado.

VII

mas no de estotra parte: ley severa

que puede:

cerrar los ojos.

VIII

mas de esotra parte en la ribera:

Llama que nada y llama Nada

en Agua Fría: tendrá sentido.

memoria Nada ardiendo desatada: tendrá sentido.

Cuerpo en llama que sabe

nadar Nada en Agua Fría: tendrá sentido.

polvo-Nada: ceniza-Nada ardiendo: tendrá sentido.

Dios-Llama que nada y llama Nada:

tendrá sentido.

De entre todas sus obras, El Riseñor, poemario al que pertenece «Las dos orillas ${ }^{17}$, se caracteriza por el protagonismo de poemas célebres, a menudo clásicos, en todas sus reescrituras. Junto a «Las dos orillas», que recoge fragmentos de «Amor constante más allá de la muerte», «La espada» retoma algunos de “Miré los muros de la patria mía»: escoge poemas graves, no burlescos, sin someterlos a su característica parodización.

Atendiendo a aquellos procedimientos antes esbozados y aplicados a los versos de Octavio Paz, el poema «Las dos orillas» recupera, en

17. El nombre original de este poema, tal y como figura en El Riseñor, es «Las dos riberas». «Las dos orillas» corresponde a la versión aquí tratada, publicada en los Episodios (1980). 
primer lugar, el léxico del poema original sin apenas contribuir a su enriquecimiento. Desde los términos más generales como prisión, agua y sombra, hasta otros más particularmente quevedescos como postrera, medulas, gloriosamente, polvo y ceniza, el poema está plenamente integrado por los términos originales.

En lo relativo al segundo procedimiento, referido a los conceptos y connotaciones, los versos originales del español son desmembrados y sus términos recombinados, fragmentando violentamente sus estructuras sintácticas y semánticas para abrir paso a una posibilidad de significados y de resoluciones potenciales de aquellas oraciones que quedan interrumpidas, mutiladas. Los conceptos, por otra parte, también recombinados en muchas ocasiones, son transformados a través de poderosas dilogías: «alma-prisión» y "postrera sombra» pueden remitir a la detención y a la cárcel; "postrera sombra» y “cerrar los ojos», a su vez, a la muerte; «cerrar los ojos» y «ley severa», al olvido; «ley severa», a su vez, a la represora fuera dictatorial. Como es apreciable, algunos conceptos como "alma-prisión», «Dios-Llama», "Dios-toda-llama», "polvo-nada», se originan por composición; no hay, sin embargo, una producción de neologismos en sí tal como encontraremos en el poema siguiente.

Así el tercer procedimiento, el del uso de estructuras y recursos, queda plasmado en estos versos que extreman el hipérbaton quevedesco -sirva prácticamente la completa extensión del poema como ejemplo-, el encabalgamiento más abrupto -reitero lo anterior-, y las antítesis -junto a las recuperadas del poema original, como la que contrapone aunando en un mismo cuadro «la llama que nada en agua fría», el poema en su misma estructura profunda deviene una gran antítesis-. Términos, conceptos, estructura e innovación son retomados; algo particular ocurre con la estructura del poema, destinada a remarcar la cualidad más propiamente espacial de la composición a través de una organización por contraposición de dos espacios: «esotra parte en la ribera» y su lógicamente consecutiva «estotraparte». Los espacios quevedescos suelen ser producto de la introspección, galerías interiores que tan a menudo se manifiestan en los viajes de conciencia del yo poético; en este soneto las referencias interiores se enriquecen gracias a la creación imaginativa de una geografía del Hades.

Al mencionar las complejas paradojas y ambigüedades del poema de Quevedo, son pocos los críticos que al tratar su espacialidad inciden en la dicotomía de las partes de la metafórica ribera: «esotra parte» y "en donde ardía» dan lugar a dos opciones: a que se trate del mismo lugar, lo que indicaría que ambos estarían refiriéndose al mundo terrenal de los vivos «donde [la llama] ardía» -no dejará allí donde estaba, en esotra parte (lugar donde ardía la llama) a la memoria-; o a que se trate de dos espacios, caso en el que (en donde ardía» sería una vez más referente del mundo terrenal, y «esotra parte» del mundo de los muertos -estando en esotra parte, no dejará la memoria allí en donde ardía, sino que se la llevará-. El problema lo provocan la sintaxis, que 
impide conocer con certeza cuál sea el sujeto -«la postrera sombra» o «esta alma mía» - y la formulación preposicional «en», «de», así como la extraña formulación temporal del poema.

Esta confusa situación, que puede no tener una gran trascendencia en el poema de Quevedo, pues resulta fácil resolverla tomando el segundo de los casos, sí lo tiene en el de Lamborghini: «Las dos orillas» contiene unos referentes semánticos que indican una deíxis de la lejanía -«esotra»- y otra de la cercanía -«estotra»-. La importancia reside en cuál sea la orilla en la que el yo poético se sitúe. De un modo natural, debido a ese contenido deíctico, cabe entender que el yo poético de Lamborghini se sitúa en «estotra parte», aquella que encierra en su orilla el sinsentido, el estatismo, la cerrazón y la amenaza: todo apunta a que se trata de la vida en Argentina bajo la dictadura. Cárcel, muerte, exilio, olvido, dictadura, emergen entre los versos quevedescos. Por otro lado, «esotra parte» constituye también un espacio confuso por sus ambivalencias, pero sin duda de signo positivo -alberga aperturismo, libertad, movilidad y metamorfosis-, como reza la última estrofa: «tendrá sentido». Superación de aquella negativa «estotra parte», y perpetuación del ser, este espacio figurado puede metaforizar tanto el exilio -sin cadenas- como, de un modo inverso al poema original -según el cual el Hades quedaba en (esotra parte en la ribera»-, la muerte, una muerte liberadora que supone el descanso definitivo. La verdadera prisión, la verdadera tortura se encuentra en cestotra parte»: Quevedo y Lamborghini están refiriéndose, en fin, a dos espacios diferentes empleando una misma terminología y retórica: el Hades y la Argentina reprimida y torturada, el particular infierno de Lamborghini.

\subsection{Juan Gelman}

Juan Gelman ${ }^{18}$ integra en su poesía, como Lamborghini, una intertextualidad variada a través tanto de alusiones a otros discursos, como de incorporaciones de los mismos, como señala Sillato:

Gelman adopta y adapta discursos previos en un proceso dinámico de enriquecimiento de su propio texto a partir de las connotaciones que tales discursos producen dentro de un contexto diferente a aquel en el que surgieron originariamente ${ }^{19}$.

18. La vida de Gelman estuvo vinculada desde la juventud tanto a la literatura como a la política: fue temprana su politización y participación en grupos comunistas, peronistas y guerrilleros - como la Far, y más tarde los Montoneros-. En los años de la dictadura, durante los cuales Gelman debió permanecer exiliado, se produjeron nuevos sucesos que marcaron definitivamente su vida y obra: el secuestro por parte del gobierno dictatorial de su hija Nora Eva, su hijo Marcelo Ariel y su nuera embarazada, María Claudia; la suerte de liberación que corrió la primera no la tuvieron Marcelo y Claudia, asesinados ambos en campos de concentración, dando ésta a luz a una niña que Gelman no logró localizar hasta el año 2000: su nieta Andrea.

19. Sillato, 1996 , pp. 79-80. 
Gran parte de la producción de Gelman, especialmente aquella compuesta en las décadas de los 70 y 80, gira en torno a los temas de la dictadura, las desapariciones y el exilio ${ }^{20}$ : Hechos -poemas escritos entre 1974 y 1978, publicados en 1980-, Notas, Carta abierta y Si dulcementetítulo que terminó por englobar los poemas de los otros dos, publicados también en 1980-, Citas y comentarios -de los años 1978-1979- son una muestra de ello. Fue por ello que la «visión exiliar» latente en los versos de poetas místicos descendientes de judíos conversos -condición que compartía Gelman- como santa Teresa y san Juan de la Cruz, fue la más adecuada para expresar la propia condición ${ }^{21}$. También la poesía de poetas judíos y judeo españoles medievales como Eliezer ben Jonon, Salomón Ibn Gabirol, y Yehuda Halevi, e incluso el tango, por sus mensajes de abandono y dolor, fueron susceptibles de filtrarse en la poesía de Gelman (Montanaro, 2006): en fin, una heterogénea conjunción de tradiciones tan dispares como las que adoptaba Lamborghini, que comparten el tono de pesadumbre por la ausencia de lo amado que Gelman traduce en la lejanía de la patria y en la pérdida de sus seres queridos.

La forma en la que Gelman introduce estos discursos en su poesía tiene puntos en común con la de Lamborghini: reescritura, adopción de términos, de estructuras sintácticas reconocibles, de recursos retóricos, de conceptos que se abren a nuevos universos de significado; fracturación de las oraciones a través de barras que quiebran bruscamente su sentido y las dejan en ocasiones en suspensión -campo abierto a la interpretación, pero también desesperanza de un devenir truncado-; signos de puntuación que, a diferencia de Lamborghini, desaparecen provocando un desconcierto similar al de aquellos arbitrariamente situados. Tan sólo la interrogación se mantiene, una que se origina en su poesía como recurso retórico, pero que acaba adoptando otra significación: «es difícil descifrar si preguntan o afirman [...] blasfeman, denuncian [...] ponen en evidencia, atenúan las ausencias, el miedo, las desesperanzas, las derrotas y las pérdidas »22. A estos recursos se suma una constante destrucción y recomposición del léxico.

Si dulcemente ${ }^{23}$ es un poemario de duelo por una (mitad perdida»: el hombre, microcosmos «integrado como un todo», es fracturado por el exilio, dividido en un fragmento «con el que debe asumir lo contingente de la vida cotidiana», y otro «vivo sólo en lo ilusorio de la memoria»: «El pasado entonces deviene epifanía, culminación, sombra, himno: la mitad perdida» ${ }^{24}$. También de duelo por la pérdida de los seres queridos, familia y amigos escritores ${ }^{25}$, que son nombrados bajo el término

20. Ver Fabry, 2012 y Gómez Mando, 2004.

21. Sillato, 1996, p. 89.

22. Montanaro, 2006, p. 64.

23. Gelman, Si dulcemente, Barcelona, Lumen, 1980.

24. Tamargo Cordero, 2000, p. 11.

25. Compañeros reiteradamente reclamados a través de sus versos: Paco Urondo, escritor, periodista, guerrillero y militante político, asesinado en 1976; Rodolfo Walsh, 
(compañeros»: un duelo que nunca termina, una pérdida de eco infinito en la conciencia, que alarga para siempre la incertidumbre y mantiene el dolor vivo por las circunstancias en las que se producen estas ausencias -raptos, «desapariciones», asesinatos-, que impiden la realización de un acto que oficialice las muertes ${ }^{26}$. Gelman reconstruye con sus versos una realidad destruida y fragmentada, y el amor, la muerte y el recuerdo se transforman en omnipresencias abrasadoras. Dada esta conjunción de temas y tono no sorprende que los versos de “Amor constante más allá de la muerte» conformaran el epígrafe original de Si dulcemente en su primera edición de 1980. Algunos versos, términos y estructuras del poema de Quevedo reaparecen también en los poemas «Nota XI», «Nota XXII» $\mathrm{y}$ «Nota XXIV», en los que se aprecian, de modo conjunto, los procedimientos ya dos veces aplicados.

La recuperación léxica es general: una vez más, desde memoria, alma, amor, presentes en todos, a «ley severa» o «agua fría» en la «Nota XXIV». Sin embargo, son numerosas las aportaciones de Gelman, en contraste con las de Lamborghini: sangre, pueblo, resistencia («Nota XI»), exiliados, huesos, pedacitos («Nota XXII») o muertitos («Nota XXIV») revelan con fuerza y de un modo directo esta nueva realidad a la que el dolor antiguo se aplica.

Conceptos como ley severa o agua fría - en la «Nota XXIV»- conservan su connotación peyorativa, aunque remiten a realidades nuevas, como ocurría en el poema visto en la sección anterior.

«Nota XXIV»

a la derrota o ley severa mi alma sabió perder respeto/te amo/ cruza mi alma la agua fría donde flotan los rostros de los compañeros como envolvidos de tu piel la suave o lámpara subida delicada para que duerman delicadamente subidamente en vos/llama que nombra a cada sombra por su nido/dicha o soledad de fuego para amor donde descansen bellos mis muertitos que siempre amaron rostros como vos donde tu rostro avanza como vos contra la pena de haber sido/ser

La «Nota XXIV» es la que mejor recupera la rebeldía del alma amante quevediana, rebeldía ante la «ley severa» - ¿la muerte? ¿la dictadura?

escritor, periodista y guerrillero, desaparecido en 1977; Haroldo Conti, novelista secuestrado, desaparecido en 1976.

26. «vení tristeza / matame vos los muertos que / mochileo con toda el alma / o terminalos de matar ya / que la gente sigue / como paisaje o voz que no se calla // gente que no termina más» («Nota VII»). 
¿su intento de olvido?-, aparentemente irremediable. Su fortaleza y determinación nacen, como las del yo poético de Quevedo, del amor. Este es elevado frente a la injusticia y la muerte, frente a los intentos del gobierno por borrar la realidad: eleva un amor que es memoria. Junto al concepto de la «ley severa», la del «agua fría» que es franqueada, una que amplía sus referentes: agua de los ríos del Hades, y agua también del Río de la Plata, dos ríos de la muerte. Los infiernos alcanzan en el mundo terrenal las playas de Argentina.

En lo relativo a la estructura de estos poemas, resulta sorprendente que, a pesar de la irregularidad formal del poemario, precisamente las «Nota XXII» $\mathrm{y}$ «Nota XxIV» se compongan, aunque de versos libres sin rima, de dos cuartetos y dos tercetos, siguiendo la huella del soneto clásico quevedesco. Hipérbaton y encabalgamientos, como en el poema de Lamborghini, se hacen por sus características tanto externas -rebeldía formal- como internas -fragmentación emocional- inevitables. En la «Nota XI» se expresa la desorientación ante una memoria y una realidad que no concuerdan - una realidad de violencia y una memoria impoluta manipulada desde el poder-:

« ¿a la memoria le falta realidad / a la realidad le falta memoria? / ¿qué hacer con la memoria / con la realidad en la mitad de esta derrota o alma? alma a quien todo un pueblo sangre ha sido del olvido nace una flor gorda marron<smiles>[CH]1[CH]C=C1</smiles>
de la memoria crecen resistencias.

En la «Nota XXII» se expresa la realidad de los exiliados, seres desorientados que han perdido su identidad y vagan sin rumbo. Como en el anterior poema, las estructuras sintácticas de Quevedo y sus términos se fragmentan y vuelven a solidificarse en una disposición distinta:

huesos que fuego a tanto amor han dado exiliados del sur sin casa o número por el dolor pasean como niños bajo la lluvia ajena / una mujer habla en voz baja con sus pedacitos como acunándoles el no ser.

Los «huesos»-y «huesitos»-, «los pedazos» y «pedacitos» de los compañeros rotos, «muertitos», definen la nueva metafísica del ser y su composición: el no ser fragmentado que habita los restos de un cosmos devastado, cosmos de ruinas ${ }^{27}$. La memoria resiste frente a quienes tra-

27. Se aprecia una evolución en el modo de nombrar a estos compañeros: al principio del poemario es más común que, además de aparecer repetitivamente el término «compañeros», aparezcan sus nombres propios: «Paco», «Rodolfo», «Haroldo». Pronto 
tan de borrar el crimen: «va a haber que trabajar limpiar huesitos / que no hagan negocio con la sombra / desapareciendo» («Nota II»). Y con la memoria resiste un amor: uno que a diferencia del de Quevedo -del amante en su muerte por la amada viva- recupera la muerte del ser amado del Canzionere, y la eternidad del amor tanto in vita como in morte.

Aunque de un modo sutil, términos, conceptos y estructuras sintácticas son retomadas en estos poemas, creando un reclamo a una intertextualidad que enriquece el nuevo poema con sus connotaciones, ya conocidas por el lector habitual de poesía. Como el tono, correspondiente al último de los procedimientos, también los recursos expresivos de Gelman se asemejan a los de Quevedo: la violencia que suponen los términos agramaticales -consecuencia terminológica de una visión degradada de la realidad-, como los verbos mal conjugados -«sabió»-, la fragmentación y el encabalgamiento, el hipérbaton de la oración larga enfrentada al laconismo de otros versos, la hipérbole, las imágenes fúnebres, la repetición -pleonasmos con términos mortuorios-, y el uso de diminutivos que contrastan con la gravedad de los poemas aportando un tono infantil y cariñoso. A todos ellos se suma la creación de los neologismos mencionada, de entre los que resultan especialmente interesantes «vivimorís» y «moriviviste», producciones morfológicas antitéticas, creadas por medio del procedimiento de la composición de lexemas, que abren ese nuevo mundo de posibilidades existenciales: la vida en la muerte, la muerte en la vida, de un modo parecido al que Quevedo proponía la existencia del sujeto amante, muerte en vida, y la muerte de ese mismo sujeto, vida emocional en muerte.

\section{BibLiografía}

Acereda, Alberto, «De Quevedo a Darío. Resonancias líricas y actitud vital», La Perinola, 5, 2001, pp. 11-23.

Carpentier, Alejo, «Lo real maravilloso», El reino de este mundo, Madrid, Alianza Editorial, 2003.

Chiampi, Irlemar, Barroco y modernidad, México, Fondo de Cultura Económica, 2000.

Elissagaray, Alejandro, La poesía de los 80, Texas, Editorial Nueva Generación, 2002.

Fabry, Genevieve, «Convivir con la muerte: la poesía de duelo de Juan Gelman», en Juan Gelman. Poética y gramática contra el olvido, coord. Aníbal Salazar Anglada, Sevilla, Universidad de Sevilla, Secretaría de Publicaciones, 2012, pp. pp. 141-156.

Fondebrider, Jorge, «Treinta años de poesía argentina», Revista de Literatura Hispánica, 52-53, 2001, pp. 5-31.

pasa a denominárseles también «muertos»; no es hasta la «Nota viıI» cuando se atreve a referirse a ellos como «cadáveres», y como tales susceptibles de experimentar una serie de procesos naturales; más adelante, son huesos, y son sombras que habitan en un espacio intermedio entre la vida y la muerte. 
García Valdés, Celsa Carmen, “Quevedo en América. Bibliografía inconclusa», La Perinola, 13, 2009, pp. 17-52.

Gelman, Juan, Si dulcemente, Barcelona, Lumen, 1980.

Gómez Mando, Edmundo, El llamado de los desaparecidos. Sobre la poesía de Juan Gelman, Montevideo, Cal y Canto, 2004.

González, Ricardo, La poesía de Leónidas Lamborghini, Buenos Aires, Leos, 1999.

Herrera, Arnulfo, «Dos apuntes sobre el influjo de Quevedo en los poetas novohispanoamericanos», La Perinola, 7, 2003, pp. 209-239.

Lamborghini, Leónidas, El riseñor, Buenos Aires, Argentinos, 2012.

Montanaro, Pablo, Juan Gelman. Esperanza, utopía y resistencia, Buenos Aires, Lea libros, 2006.

Paz, Octavio, “Salamandra» (1958-1961), La centena (Poemas de 1935-1968), Barcelona, Barral Editores, 1969.

Porrúa, Ana, Variaciones vanguardistas. La poética de Leónidas Lamborghini, Rosario, Beatriz Viterbo, 2001.

Quevedo, Francisco, Poesía metafísica y amorosa, ed. José Manuel Blecua, Madrid, Cupsa Edición, 1976.

Seoane, María, El dictador, Buenos Aires, Sudamericana, 2001.

Sillato, María del Carmen, Juan Gelman: las estrategias de la otredad, Rosario, Beatriz Viterbo Editora, 1996.

Tamargo Cordero, Elena, Juan Gelman: poesía de la sombra de la memoria, México, D.F., Universidad Iberoamericana, Departamento de Letras, 2000. 
